\title{
LICENCIAMENTO DE VEÍCULOS E SEU IMPACTO NA CADEIA PRODUTIVA DO SETOR AUTOMOTIVO: ESTUDO DE CASO EM UMA INDÚSTRIA DE VIDROS
}

\author{
C.R. Santos ${ }^{1,}$; A.B. Moura ${ }^{1}$; M.V. Nascimento ${ }^{1}$
}

\author{
1 Faculdade de Tecnologia de São José dos Campos - Professor Jessen Vidal \\ Av. Cesare Mansueto Giulio Lattes, 1350 - Eugênio de Melo, São José dos Campos/SP, \\ CEP. 12247-014, Brasil. \\ Telefone: (12) 3905-2423 \\ *cristianramossantos01@gmail.com
}

\begin{abstract}
RESUMO: O setor automotivo é de grande importância para a economia do Brasil representando $4 \%$ do PIB nacional e gerando em torno de 1,6 milhão de empregos. O comportamento da produção de veículos afeta significativamente o setor de autopeças, reforçando a importância de se entender o funcionamento do setor para uma boa gestão de estoques em todos os níveis. $\mathrm{O}$ presente estudo teve como objetivo verificar o comportamento da venda de veículos e analisar seu impacto na cadeia produtiva. $\mathrm{O}$ ambiente de aplicação do estudo foi uma empresa do setor de vidros. Para alcançar esse resultado utilizou-se a regressão linear e, a partir do modelo gerado, aplicou-se na empresa em estudo. Os resultados apontaram que é possível se estimar o valor de estoque da empresa de vidros para um componente fundamental da produção de vidro automotivo por meio do número de licenciamentos.
\end{abstract}

PALAVRAS-CHAVE: estoque; gestão; automotivo; autopeças; veículos.

ABSTRACT: The automotive sector is of great importance for the Brazilian economy, representing $4 \%$ of the national GDP and generating around 1.6 million jobs. The management of vehicle production significantly affects the auto parts industry, reinforcing the importance of understanding the sector's operations for good inventory management at all levels. The present study aimed to verify the management of vehicle sales and analyze their impact on the production chain. The application environment of the study was a company of the glass sector. To achieve this result, linear regression was used and, based on the generated model, it was applied in the study company. The results showed that it is possible to estimate the stock value of the glass company for a fundamental component of automotive glass production through the number of licenses.

KEYWORDS: stock; management; automotive; auto parts; vehicles.

\section{INTRODUÇÃO}

O setor automotivo é um dos principais geradores financeiros para a economia nacional. De acordo com o Ministério da Indústria, Comércio Exterior e Serviços (MDIC, 2018), o setor representa $22 \%$ do Produto Interno Bruto (PIB) industrial e 4\% do PIB Total, gerando em torno de 1,6 milhão de empregos. Segundo a Associação Nacional dos Fabricantes de Veículos Automotores, ANFAVEA (2018), em 2017 o Brasil apresentou o maior número no histórico de exportações, sendo 61,1 mil unidades exportadas. Há uma perspectiva de crescimento para o ano de 2018 de 5\% e 13,2\% na exportação e na produção, respectivamente. Ainda conforme o relatório da ANFAVEA (2018), a 
possibilidade de crescimento da economia e da indústria automotiva é esperada, principalmente devido à queda inflacionária, a estabilidade cambial e a espera de aumento do PIB.

No Brasil, a fabricação de veículos é tomada por multinacionais. Como consequência, isso faz com que as matrizes estrangeiras sejam responsáveis pelas decisões estratégicas a serem tomadas. Ainda assim, o Brasil possui um conjunto de atividades integradas que possibilita o desenvolvimento e fabricação regional de uma grande parcela do veículo (BARROS e PEDRO, 2011).

Castro et al. (2017) aborda em sua pesquisa a importância do planejamento estratégico devido empresas nacionais serem dependentes dos processos de importação impactando de forma significativa a produção interna, principalmente em períodos de flutuação cambial. Em 2014, os segmentos que representaram essa importação foram motor, transmissão, chassi e carroceria, elétrica e eletrônica e, rodas e pneus (BARROS, CASTRO e VAZ, 2015).

Outro aspecto a ser levado em conta, é o efeito em cadeia que o estoque de produtos acabados sofre em períodos de crise, onde o aumento dos preços dos insumos atinge de forma direta o custo de produção (BARROS, CASTRO e VAZ, 2015). Ainda sobre o estudo de Barros, Castro e Vaz (2015), as montadoras são responsáveis por grande parte do faturamento do setor de autopeças, por consequência, a fabricação de veículos novos atinge vigorosamente a cadeia deste setor.

\subsection{Objetivo Geral}

O objetivo deste trabalho é elaborar um modelo estatístico via regressão linear que permita estimar o efeito da venda de veículos novos na flutuação do estoque de uma indústria de vidros que abastece o setor automotivo.

Para a consecução deste objetivo foram estabelecidos os objetivos específicos:

- Realizar uma pesquisa sobre o histórico do setor automotivo no Brasil;

- Levantar dados necessários para a construção do modelo econométrico entre os anos de 2016 e 2018;

- Desenvolver análise estatística dos dados levantados.

\subsection{Proposta Metodológica}

Para atender os objetivos deste trabalho, a metodologia de pesquisa utilizada foi estruturada em quatro pilares: natureza, abordagem, objetivos e procedimentos técnicos.

Quanto a natureza, adotou-se uma pesquisa descritiva e aplicada, que tem por objetivo trazer conhecimentos para aplicação prática. Quanto a abordagem, trata-se de uma pesquisa qualitativa e quantitativa. Segundo Minayo (2001), a pesquisa qualitativa trabalha com aspectos da realidade que não podem ser quantificados. Já a quantitativa utiliza uma linguagem matemática que, associada à pesquisa qualitativa, possibilita encontrar mais informações do que se conseguiria utilizando apenas a quantitativa (FONSECA, 2002). A pesquisa é descritiva e explicativa quando se refere ao objetivo. Para Gil (2007) a pesquisa explicativa busca identificar e explicar as ocorrências por meio dos resultados obtidos sendo a continuação da descritiva. Para dar início ao trabalho é necessário uma pesquisa bibliográfica, onde é feito buscas por estudos e referências teóricas que já foram publicadas para estruturar o assunto a ser estudado e, por último, a pesquisa de levantamento, que pode ser levantamento de uma amostra ou uma população (FONSECA, 2002). Como pode-se observar na Figura 1. 


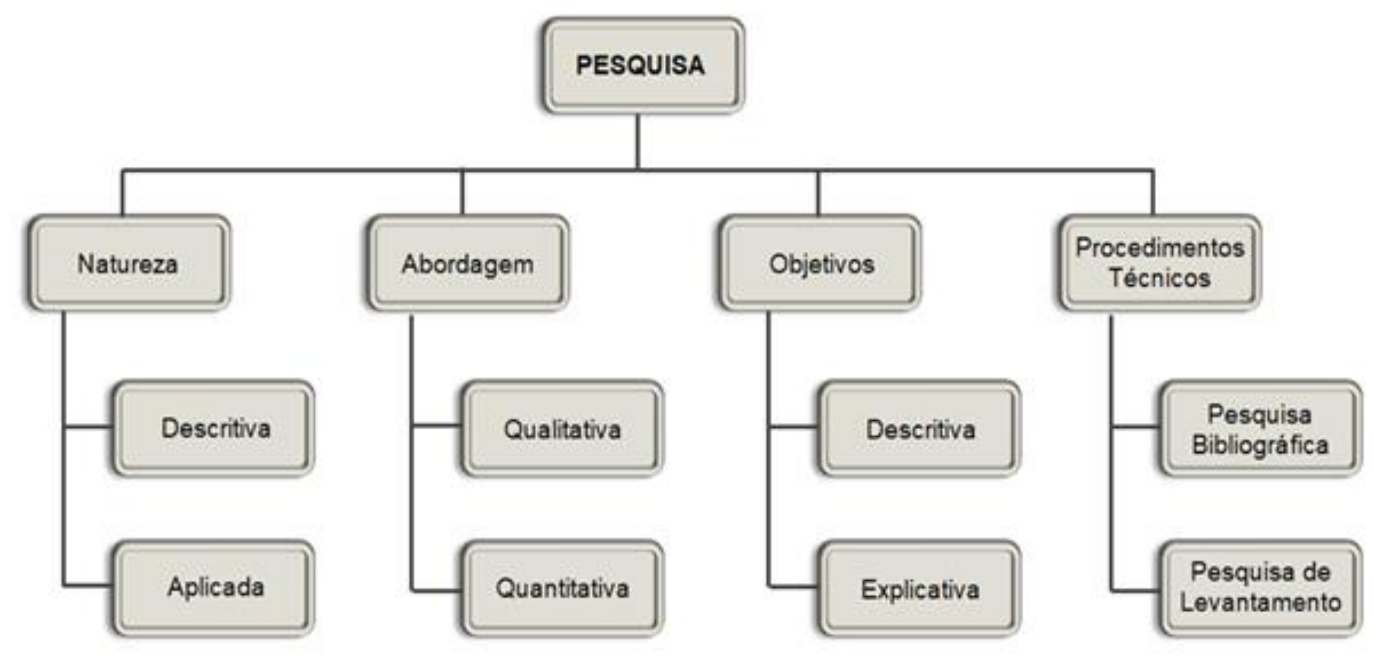

Figura 1. Proposta metodológica

\subsection{Conteúdo do Trabalho}

O presente trabalho está estruturado em cinco Capítulos, cujo conteúdo é sucintamente apresentado a seguir:

O Capítulo 1 apresenta introdução, contextualização e objetivos do trabalho.

No Capítulo 2 é feita a fundamentação teórica sobre a história do setor automotivo e sua cadeia de suprimentos.

O Capítulo 3 apresenta a base de dados levantada para a realização do estudo em questão.

No Capítulo 4 é desenvolvido aplicação através de ferramenta econométrica.

Finalmente, o Capítulo 5 apresenta as conclusões deste trabalho a partir da análise dos resultados obtidos.

\section{REVISÃO DA LITERATURA}

A cadeia produtiva da indústria automobilística foi considerada uma das mais atraentes servindo como modelo para companhias industriais e gerenciais e, tornou-se relevante para o conceito produtivo em grandes volumes devido sua flexibilidade (WOMACK, JONES e ROOS, 2004).

O comportamento do setor automotivo pode atingir consideravelmente outras áreas manufatureiras que estão ligadas direta ou indiretamente à produção de automóveis. Entre os insumos por exemplo, estão o setor de aço e derivados, que são um dos mais importantes para a cadeia produtiva. Outras áreas que se destacam são as de máquinas e equipamentos, materiais eletrônicos, produtos de metal, borracha e plástico (MDIC, 2018). Esse é um setor que necessita constantemente buscar processos mais confiáveis, rápidos e flexíveis, pois a agilidade e eficiência influencia na competitividade das montadoras (ZILBOVICIUS e ARBIX, 1997). O capítulo seguinte trata de uma breve apresentação do setor automotivo no Brasil, demonstrando os movimentos econômicos e suas influências para o setor.

\subsection{Setor Automotivo no Brasil}

A implantação do setor automobilístico no Brasil teve início em 1957 e, a partir da década de 1980 surgiu o processo de abertura comercial, por conseguinte, aumentou a concorrência interna e perdurou até o ano de 1997 como reação à transformação pela qual o mercado mundial passou na década de 1990 (ZILBOVICIUS e ARBIX, 1997). 
Em 1995 iniciou-se um período de expansão e investimento para as montadoras de automóveis, ao mesmo tempo, o setor de autopeças, que produziam peças de reposição para veículos importados antes de iniciar a produção de automóveis no Brasil, começou a se fortalecer. Foi quando várias indústrias se estabeleceram em lugares do Brasil onde não havia prática no setor automotivo. Nessa fase, o setor automobilístico passou por uma renovação significativa (POSTHUMA, 1997).

No final do ano de 2008 surgiu repentinamente uma crise financeira no mundo que prejudicou muito o setor em questão. No Brasil, o efeito da crise teve início em outubro com a queda nas vendas de 6,7\% comparado ao mesmo intervalo de tempo do ano de 2007. Mesmo com a crise permanecendo em 2008, o mercado automotivo alcançou números relevantes, passando de 3 milhões de auto veículos produzidos (BARROS e PEDRO, 2011).

Em 2009 o setor sofreu uma pequena queda, em torno de $1 \%$ na produção. Porém houve um aumento de $11,4 \%$ nas vendas internas firmando o Brasil como o $5^{\circ}$ maior mercado mundial. A eficiência do mercado interno levou o país ao $4^{\circ}$ maior mercado mundial em 2010. Em 2011, produção e vendas cresceram integradas à projeção de aumento do PIB.

Devido ao tamanho do mercado e seu padrão tecnológico, as montadoras tendem a ser de grande porte, e estão voltadas para o alcance de economias de escala. Os centros de tomadas de decisões e de planejamento e desenvolvimento localizam-se nos países sede, e as indústrias são distribuídas internacionalmente buscando atender as necessidades do mercado final (MDIC, 2018).

Segundo a ANFAVEA (2018), com a saturação do mercado nos países desenvolvidos, os emergentes, com melhor infraestrutura, tornaram-se centros regionais de produção e distribuição, possibilitando o atendimento não só do mercado local, mas também de países da região. O que resultou em maiores investimentos externos no BRICS: Brasil, Rússia, Índia, China e África do Sul.

\subsubsection{Distribuição Geográfica do Setor Automotivo no Brasil}

De acordo com o Anuário da Indústria Automobilística Brasileira (2018), foi verificada a distribuição das unidades industriais no ano de 2017 onde, as 27 empresas que são associadas à Anfavea agrupam 65 indústrias que incluem a produção de autoveículos, máquinas agrícolas e rodoviárias, motores, componentes e outros produtos, e estão localizadas em 10 estados e 42 municípios. Na região do Nordeste encontra-se 3 indústrias sendo 1 no estado da Bahia, 1 no Ceará e 1 em Pernambuco. Em Goiás estão situadas 3 unidades industriais totalizando a região CentroOeste. No Sudeste é onde está a maior concentração produtiva do setor, 36 unidades, são 4 indústrias no estado de Minas Gerais, 5 no Rio de Janeiro e 27 no estado de São Paulo. No Sul do país encontram-se 11 unidades no estado do Paraná, 10 no Rio Grande do Sul e 2 em Santa Catarina, totalizando 23 indústrias na região Sul, conforme Figura 2.

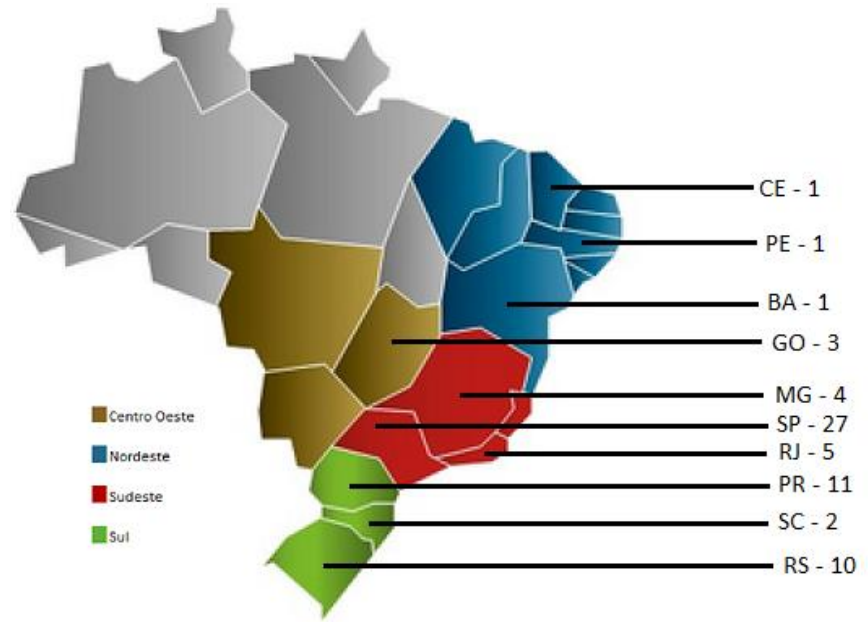

Figura 1. Distribuição de empresas por estado 
Segundo o Ministério da Indústria, Comércio Exterior e Serviços (2018), além das unidades de produção de veículos, foram contabilizados 590 produtores de autopeças e 5592 concessionárias no ano de 2017. O estudo realizado por Santos, Luccio e Nascimento (2018), reforça a relevância do Estado de São Paulo. Os autores indicam 27 unidades fabricantes e 344 fornecedoras do setor automotivo, no Estado.

\subsubsection{Cadeia Produtiva da Indústria Automotiva no Brasil}

A cadeia de suprimentos no Brasil é composta por fornecedores, montadoras, concessionárias e clientes (GUARNIERI e HATAKEYAMA, 2005). A Figura 4, seguinte, apresenta uma estrutura simplificada da cadeia de suprimentos do setor automotivo.

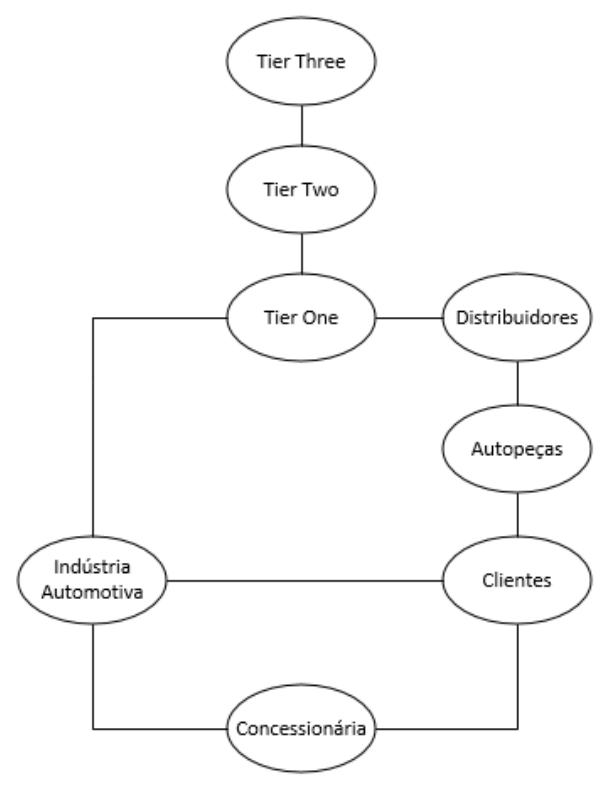

Figura 2. Cadeia de suprimentos do setor automotivo

Existem três camadas (Tier) de configuração para os fornecedores do setor automobilístico conforme Barros, Castro e Vaz (2015).

- Tier One - fornecedores direto para a empresa fabril

- Tier Two - fornecedores do Tier One

- Tier Three - fornecedores do Tier Two

Segundo Ballou (2006), desde o fluxo de recebimento da matéria-prima até o consumidor final, bem como o processo de transformação do produto, são partes que integram a cadeia de suprimentos. O gerenciamento deste fluxo cabe à integração entre as áreas de Marketing, logística e produção, gerando melhorias e aumentando a vantagem competitiva.

De acordo com Guarnieri e Hatakeyama (2005), as atividades dentro de uma cadeia de suprimentos englobam desde o pedido do cliente até o descarte adequado do produto, divididas entre as atividades principais que são o processamento dos pedidos e a gestão de estoque e as de apoio que cabem à movimentação interna dos produtos.

\subsection{Incentivo Fiscal no Setor Automobilístico no Brasil}

Os incentivos fiscais são prerrogativas oferecidas pelo governo a determinadas empresas com o intuito de fomentar um setor ou atividade específica, seja através de redução de impostos, isenção ou compensação. De acordo com o Banco Nacional do Desenvolvimento - BNDES (2016), o governo tem esses incentivos como uma relevante ferramenta que viabiliza o crescimento econômico e social, 
possibilitando que as empresas beneficiadas invistam em suas operações, o que aumenta o número de contratações e faz a economia girar.

A Indústria automobilística no Brasil vem se destacando nos últimos anos com a criação de novas políticas públicas, estímulo para desconcentração regional e a redução de impostos. Em 1996 iniciou-se a desconcentração regional através do "Regime Automotivo Regional ou Espacial" (Medida Provisória 1.532), incentivando a instalação das montadoras nas regiões Norte, Nordeste e Centro-Oeste através da redução de impostos de importação de peças e componentes, isenção/redução de IPI, IR e IOF na aquisição de matérias-primas e insumos (NEGRI, 1999).

Segundo Torres (2017), uma intervenção fiscal, como ocorreu em 2008, com a política de desoneração fiscal, e em 2012, com uma nova queda do IPI, traz uma contribuição para a melhoria da economia apenas por um breve período. Após um determinado tempo, o mercado acaba se nivelando e a ação para de gerar resultado. Sendo assim, depois de um período com o IPI em baixa, a demanda de veículos aumentou acarretando cobranças de outros impostos, o que deixou o custo total da manobra baixo. A partir daí a alíquota se estabilizou e fez parecer que o mercado que aumentou.

Em um estudo feito por Barbosa et al (2017), onde analisou-se os impactos da desoneração do IPI no setor automotivo, verificou-se que essa política não influiu na receita, o que impactou positivamente o faturamento em vendas foram o giro do ativo e COFINS. Ainda assim, pode se dizer que esta intervenção corroborou positivamente no sentido de promover uma rápida resposta do nível de atividade evitando a queda do nível de emprego. Com isso, concluiu-se que políticas fiscais não contribuem para o aumento da receita bruta de vendas da empresa, apenas age para aquecer o mercado e voltar a demanda de veículos aos parâmetros normais.

Em um estudo realizado por Coutinho e Nascimento (2018), utilizando regressão linear para descobrir o impacto das políticas de incentivos fiscais no número de automóveis estocados, os autores apresentaram resultados efetivos das políticas pré-estabelecidas. Após obter os resultados com o estudo, Coutinho e Nascimento (2018) indicaram que os incentivos fiscais influem em cerca de 20 mil automóveis a mais fabricados mensalmente. E por último, observou-se prenúncios de que não ocorre aumento ou queda conforme o tempo, já que pode se tratar de uma série estacionária.

\section{APRESENTAÇÃO E ANÁLISE DA BASE DE DADOS}

Foram coletados dados de janeiro de 2016 à junho de 2018, os quais foram retirados da ANFAVEA, de uma indústria do setor de vidros e do IPEADATA.

Os dados coletados da ANFAVEA foram o Licenciamento Nacional, que representa a venda dos veículos novos produzidos no Brasil, e a Produção total de novos veículos. Variáveis econômicas como a Taxa de Câmbio Comercial de Compra foram coletadas do IPEADATA. E, da empresa em questão, foram coletados dados de estoque de vidro e de Polivinil Butiral (PVB), os quais estão apresentados em escala.

O PVB é uma das matérias primas utilizadas na fabricação do vidro laminado utilizado nos automóveis. É uma película elástica de plástico colocada entre as placas de vidro que se aglutina através de um tratamento térmico sob pressão. Quando o vidro é danificado, os pedaços de vidro ficam grudados ao PVB, diminuindo o risco ao usuário (ASSIS, 2002).

Na Figura 5 nota-se a variação dos dados coletados. 


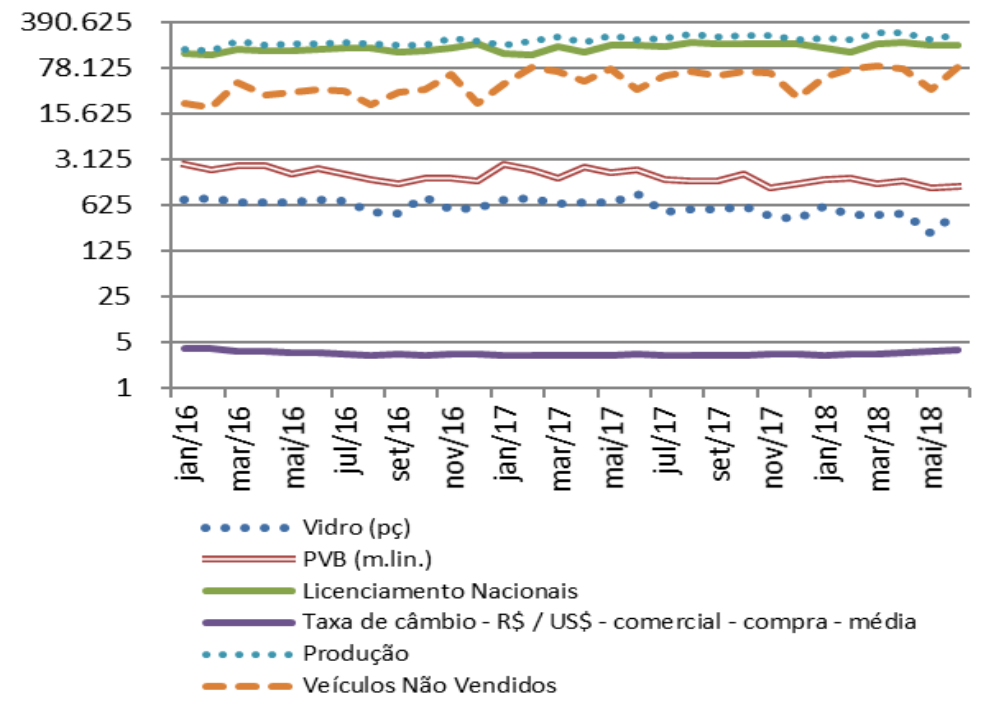

Figura 5. Gráfico variação dos dados

Por uma análise visual, conclui-se que o estoque de vidros e os veículos não vendidos são ligeiramente proporcionais pois seguem tendência semelhante. $\mathrm{O}$ mesmo ocorre com as variáveis produção e licenciamento. O estoque de PVB é proporcional ao estoque de vidro, já que são utilizados em conjunto na produção e o licenciamento é inversamente proporcional ao estoque de PVB e de vidro em alguns períodos. A análise visual de proporcionalidade será aprofundada no capítulo seguinte. De forma geral, essa análise é reflexo da tendência das variáveis. No item 4.2 é feita uma análise de correlação de todas as variáveis. O resultado da correlação evidencia o resultado da análise visual da Figura 5.

A partir desses dados foi feito um estudo estatístico para confirmar essas análises e encontrar uma equação que explique o quanto uma variável impacta a outra.

\section{ESTIMAÇÃO DO MODELO ESTATÍSTICO}

Neste capítulo será apresentado o estudo estatístico realizado. Aplicou-se um teste de correlação para analisar a conexão entre as variáveis em estudo. Após lograr o nível de relação entre as variáveis, realizou-se uma análise de regressão linear para averiguar a ligação da variável independente com a variável dependente.

\subsection{Resumo Estatístico}

O Quadro 1 apresenta informações de média e desvio padrão das variáveis em estudo.

Quadro 1. Resumo estatístico das variáveis

\begin{tabular}{|c|r|r|r|r|r|r|}
\cline { 2 - 7 } \multicolumn{1}{c|}{} & Vidro (pç) & \multicolumn{1}{c|}{ PVB $\left(\mathbf{m}^{2}\right)$} & $\begin{array}{c}\text { Licenciamento } \\
\text { Nacionais }\end{array}$ & $\begin{array}{c}\text { Taxa de câmbio } \\
\text { compra - média }\end{array}$ & Produção & $\begin{array}{c}\text { Veículos Não } \\
\text { Vendidos }\end{array}$ \\
\hline Média & 605 & 1.785 & 159.872 & 3,36 & 210.329 & 50.457 \\
\hline Desvio Padrão & 157 & 460 & 21.103 & 0,25 & 34.269 & 20.602 \\
\hline
\end{tabular}

Desvio padrão trata-se da disseminação média dos valores comparado à própria média, se o resultado for muito alto, significa que os valores estão distantes da média, e se for baixo, significa que estão próximos da média (IPEA, 2017). Analisando o volume da produção e de licenciamentos, constatou-se que em média são vendidos $77 \%$ dos veículos produzidos. Esse dado é muito importante 
para a aplicação do modelo, aumentando a possibilidade de se estimar estoque de matéria prima com base na previsão de produção de veículos.

\subsection{Análise de Correlação Entre as Variáveis}

Investigou-se o nível de correspondência entre as variáveis para posteriormente realizar a regressão linear. O Quadro 2 a seguir, apresenta os resultados obtidos.

Quadro 2. Correlação entre as variáveis

\begin{tabular}{|c|c|c|c|c|c|c|}
\hline & Vidro (pç) & $P V B\left(m^{2}\right)$ & $\begin{array}{c}\text { Licenciamento } \\
\text { Nacionais }\end{array}$ & $\begin{array}{l}\text { Taxa de câmbio } \\
\text { compra-média }\end{array}$ & Produção & $\begin{array}{c}\text { Veículos Não } \\
\text { Vendidos }\end{array}$ \\
\hline Vidro (pç) & 1 & & & & & \\
\hline $\operatorname{PVB}\left(m^{2}\right)$ & 0,771091154 & 1 & & & & \\
\hline Licenciamento Nacionais & $-0,564648281$ & $-0,643938992$ & 1 & & & \\
\hline Taxa de câmbio - compra - média & 0,075728464 & 0,281066486 & $-0,24818289$ & 1 & & \\
\hline Produção & $-0,504393453$ & $-0,578876902$ & 0,826391882 & $-0,389243382$ & 1 & \\
\hline Veículos Não Vendidos & $-0,260631035$ & $-0,303308113$ & 0,350308652 & $-0,393244741$ & 0,816906726 & 1 \\
\hline
\end{tabular}

A partir do Quadro 2 conclui-se que a variável taxa de câmbio possui uma correlação baixa entre as demais variáveis, por isso, a mesma foi excluída da regressão linear. A produção tem uma correlação forte com o licenciamento e veículos não vendidos, pois são diretamente ligados. Licenciamento nacionais e a matéria prima PVB tem uma boa correlação, o que é instigante pelo fato dessas duas variáveis não serem diretamente ligadas e não atuarem no mesmo nível de processo. Com base nesses resultados, escolheu-se o PVB e licenciamento nacionais para a aplicação do modelo econométrico.

\subsection{Modelo de Regressão}

O modelo de regressão linear foi estimado por meio de uma regressão simples entre a variáveis. O Quadro 3 mostra a regressão linear simples realizada.

Quadro 3. Regressão linear simples

\begin{tabular}{|c|c|c|}
\hline \multicolumn{2}{|c|}{ Estatística de regressão } & \\
\hline R-Quadrado & 0,414657426 & \\
\hline Observações & 30 & \\
\hline & Coeficientes & valor-P \\
\hline Interseção & 4030,58809 & 1,23988E-08 \\
\hline Licenciamento Nacionais & $-0,014047833$ & 0,000123258 \\
\hline
\end{tabular}

Nesta regressão linear considerou-se apenas a variável independente licenciamento nacionais para explicar a variável dependente Estoque de PVB.

Pelo resultado da regressão linear apresentada no Quadro 3, conclui-se, através do R-Quadrado, que $41,46 \%$ da variação no estoque de PVB pode ser explicada pela variação no licenciamento nacionais. O F de significação é bem próximo de zero, validando estatisticamente o modelo de regressão. A indicação plena da literatura é que se tenha um valor de F menor do que 0,10. Com esse estudo, considerando os coeficientes encontrados, 4030,58 e -0,01404, definiu-se o modelo matemático $\mathrm{PVB}=4030,58+(-0,01404) *$ Licenciamento nacionais.

O valor-P também está bem próximo de zero, validando a explicação entre as variáveis com $99 \%$ de confiança. 
No Quadro 4 foi realizado a aplicação do modelo matemático encontrado a partir da regressão linear, com base nos dados de estoque de PVB e licenciamentos do ano de 2016, para comprovar a eficiência do modelo.

Quadro 4. Aplicação do modelo matemático

\begin{tabular}{|c|r|r|r|r|}
\cline { 2 - 5 } \multicolumn{1}{c|}{} & PVB (m2) & $\begin{array}{c}\text { Licenciamento } \\
\text { Nacionais }\end{array}$ & $\begin{array}{r}\text { PVB (Modelo } \\
\text { Matemático) }\end{array}$ & $\%$ Desvio \\
\hline jan/16 & 2654 & 130.178 & 2202 & $17 \%$ \\
\hline fev/16 & 2174 & 125.072 & 2274 & $-5 \%$ \\
\hline mar/16 & 2557 & 153.249 & 1878 & $27 \%$ \\
\hline abr/16 & 2515 & 141.649 & 2041 & $19 \%$ \\
\hline mai/16 & 1868 & 145.663 & 1984 & $-6 \%$ \\
\hline jun/16 & 2226 & 149.583 & 1929 & $13 \%$ \\
\hline jul/16 & 1870 & 156.875 & 1827 & $2 \%$ \\
\hline ago/16 & 1561 & 159.603 & 1789 & $-15 \%$ \\
\hline set/16 & 1295 & 138.295 & 2088 & $-61 \%$ \\
\hline out/16 & 1635 & 140.247 & 2060 & $-26 \%$ \\
\hline nov/16 & 1627 & 157.652 & 1816 & $-12 \%$ \\
\hline dez/16 & 1446 & 178.831 & 1518 & $-5 \%$ \\
\hline & & & MÉDIA & $-4 \%$ \\
\cline { 4 - 5 } & & & &
\end{tabular}

Analisando os resultados da aplicação apresentada no Quadro 4, conclui-se que o modelo é satisfatório pois obteve-se um desvio médio de $4 \%$ para menos no período em questão. Em alguns meses esse desvio foi maior, como no caso do mês de setembro que apresentou um desvio de $61 \%$ para menos, esse fato pode ser explicado possivelmente por algum fator econômico inesperado ou por um período outlier da base de dados. Sabe-se, inclusive, que o ano de 2016 apresentou diversas instabilidades econômicas e políticas. Estima-se que esses fatos podem gerar impactos significativos para as variáveis em análise, porém esse efeito não foi estimado no presente trabalho. Apesar disso, o desvio médio é muito baixo, tornando o modelo eficiente para a previsão do estoque de PVB com base na previsão da produção de veículos, considerando a média de licenciamento de $77 \%$.

Outro fator que ajuda na validação do modelo é a taxa de utilização de PVB em cada veículo produzido. Os dados do estoque estão em escala, se realizar a correção dessa escala, encontra-se um valor bem próximo do que se é utilizado em cada unidade.

\section{CONSIDERAÇÕES FINAIS}

O presente estudo teve como objetivo analisar o impacto da venda de veículos na cadeia produtiva do setor automotivo e obteve como resultado, a explicação da flutuação no estoque de PVB pela flutuação do número de veículos licenciados, ou seja, veículos vendidos. Concluiu-se que através do modelo matemático encontrado pela regressão linear é possível prever o estoque da matéria prima PVB com $99 \%$ de confiança e apenas $4 \%$ de desvio.

O modelo é fortalecido por informações reais da produção que se aproxima do estimado, onde estimou-se uma quantidade de PVB para cada veículo vendido, que é bem próximo do que se utiliza para produzir cada unidade.

Esse resultado fortalece a importância da econometria no auxílio à gestão e programação de estoque, podendo avaliar o comportamento de variáveis e prever valores futuros através de modelos gerados por ela.

Em estudos futuros recomenda-se buscar mais variáveis explicativas para conseguir uma previsão mais precisa, e se possível, conseguir explicar outros tipos de estoques além do PVB. 


\section{REFERÊNCIAS}

ANFAVEA - Associação Nacional dos Fabricantes de Veículos Automotores. Exportação de Veículos Registra Melhor Ano da História em 2017, 2018. Disponível em: <http://www.anfavea.com.br/docs/05.01.18_Press_Release_Resultados_2017.pdf >. Acesso em: 19/03/2018.

ANFAVEA. Anuário da Indústria Automobilística Brasileira 2018, São Paulo, p. 152, 2018.

ASSIS, R. M. Caracterização óptica de materiais transparentes e sua relação com o conforto ambiental em edificações. Tese (Doutorado) - Universidade Estadual de Campinas, Campinas, 2002. 118 fls.

BALlOU, R. H. Gerenciamento da Cadeia de Suprimentos - Logística Empresarial. 5a. ed. Porto Alegre: Bookman, 2006.

BARBOSA, L. T. et al. Política de Desoneração do IPI e seu Impacto no Setor Automotivo e Correlatos, 2017. Disponível em: <http://www.redalyc.org:9081/home.oa?cid=141881>. Acesso em: 1/06/2018.

BARROS, D. C.; CASTRO, B. H. R. D.; VAZ, L. F. H. Panorama da indústria de autopeças no Brasil: características, conjuntura, tendências tecnológicas e possibilidades de atuação do BNDES. Produção BNDES Artigos. BNDES - O Banco Nacional de Desenvolvimento, 2015. Disponível em: <https://web.bndes.gov.br/bib/jspui/bitstream/1408/9555/1/BNDES\%20Setotrial\%2042\%20P anorama\%20da\%20ind\%C3\%BAstria\%20de\%20autope\%C3\%A7as\%20no\%20Brasil_P_P.p df>. Acesso em: 27/032018.

BARROS, D. C.; PEDRO, L. S. O papel do BNDES no desenvolvimento do setor automotivo brasileiro. Produção BNDES Artigos. BNDES - o Banco Nacional do Desenvolvimento, 2011. ISSN 1414-9230. Disponível em: <https://web.bndes.net/bib/jspui/handle/1408/1483>. Acesso em: 19/03/2018.

BNDES. O Banco Nacional do Desenvolvimento, 2016. Disponível em: <https://www.bndes.gov.br/wps/portal/site/home/conhecimento>. Acesso em: 14/05/2018.

CASTRO, G. H. et al. Multiplicadores de Importação dos Produtos da Economia Brasileira: uma análise insumo-produto para os anos 2000 e 2009. Revista Brasileira de Estudos Regionais e Urbanos, v. 11, 2017. ISSN 1981-3953 \& 2447-7990.

COUTINHO, V. D. A.; NASCIMENTO, M. V. D. Impacto das Políticas de Incentivo no Nível de Estoque de Automóveis Novos no Mercado. FATECLOG, Santos, 2018.

FONSECA, J. J. S. Metodologia da Pesquisa Científica. Fortaleza: UEC, v. Apostila, 2002.

GIL, A. C. Como Elaborar Projetos de Pesquisas. 4ª ed. São Paulo: Atlas, 2007.

GUARNIERI; HATAKEYAMA. Supplay Chain Manegement Na Indústria Automobilística. UTFPR - Universidade Tecnológica Federal do Paraná, Ponta Grossa, 2005. 
WOLFFENBÜTTEL, A. Desvio padrão. IPEA - Instituto de Pesquisa Econômica Aplicada, 2006.

<http://www.ipea.gov.br/desafios/index.php?option=com_content\&view=article\&id=2104:cat $\mathrm{id}=28 \&$ Itemid=23 > . Acesso em 26/08/2018.

MDIC - Ministério da Indústria, Comércio Exterior e Serviços. Competitividade Industrial Setor Automotivo, 2018. Disponível em: <http://www.mdic.gov.br/index.php/competitividadeindustrial/setor-automotivo>. Acesso em: 14/05/2018.

MDIC. Notícias. Ministério da Indústria, Comércio Exterior e Serviços, 2018. Disponível em: $<$ http://www.mdic.gov.br/index.php/noticias/3122-cadeia-automotiva-e-motor-paradinamizar-a-economia-nacional>. Acesso em: 27/03/2018.

MINAYO, M. C. D. S. Pesquisa Social: teoria, método e criatividade. Petrópolis: Vozes, 2001.

NEGRI, A. D. O Custo de Bem-Estar do Regime Automotivo, Rio de Janeiro, Agosto 1999. Disponível em: <http://ppe.ipea.gov.br/index.php/ppe/article/viewFile/187/121>. Acesso em: 26/03/2018.

POSTHUMA, A. C. Auto Peças na Encruzilhada: modernização desarticulada e desnacionalização. In: ZILBOVICIUS, M.; ARBIX, G. De JK a FHC: a reinvenção dos carros. São Paulo: Scritta, 1997.

SANTOS, M. H. F. D.; LUCCIO, R. S. L. D.; NASCIMENTO, M. V. D. Mapeamento da Cadeia Produtiva do Setor Automotivo: análise de concentração espacial dentro do estado de São Paulo. FATECLOG, Santos, 2018.

TORRES, T. G. B. Impactos da Redução do IPI no Setor Automotivo no Brasil: uma comparação entre carros novos e seminovos. Centro Universitário de Brasília - Faculdade de Ciências Jurídicas e Sociais, Brasília, 2017.

WOMACK, J. P.; JONES, D. T.; ROOS, D. A máquina que mudou o mundo. $11^{\mathrm{a}}$. ed. Rio de Janeiro: Elsevier, 2004.

ZILBOVICIUS, M.; ARBIX, G. De JK a FHC: a reinvenção dos carros. São Paulo: Scritta, 1997. 